\title{
Analysing the Potential of Blockchain for the Accounting Field in Indonesia
}

\author{
Abdulrival Hartoyo ${ }^{1^{*}}$, Eko Ganis Sukoharsono ${ }^{2}$, Yeney Widya Prihatiningtias ${ }^{3}$ \\ 1,2,3 Accounting department, Faculty of Economy and Business, Brawijaya University, \\ Jalan Veteran, Malang 65145, Jawa Timur, Indonesia \\ *Corresponding author; Email: abdulrival79@gmail.com
}

\begin{abstract}
This research aims to identify and analyze the potential of blockchain technology for the accounting field in Indonesia. This research was conducted at the Indonesian Blockchain Association. This research uses qualitative methods with the case study approach and analysis of making explanation strategies. The result of this study indicates that blockchain is applicable in Indonesia without having to use cryptocurrency as a payment tool. The result finds that blockchain can be used as a technology for Accounting Information System. One of the reasons is that all accounting transactions have the potential to be traceable with the blockchain. The data in this technology can be considered as relevant information due to the nature of blockchain as a technology that records and stores data that cannot be changed and manipulated. Blockchain will be used as a database and data procession will still be carried out by using the Accounting Information System. Blockchain is unable to automatically process data into information that may be needed in accounting. This research is expected to strengthen the theory related to blockchain as one of the accounting technologies, also to be an initial step in improving the concept of triple-entry accounting that is usable in Indonesia by using Blockchain which is supported by other platforms such as ERP and uses Token as the representative of assets or financial in recording transactions.
\end{abstract}

Keywords: Blockchain technology; accounting information system; triple-entry accounting.

\section{INTRODUCTION}

Blockchain technology in Indonesia has been growing continuously. It can be seen from several companies that have formed the Indonesian Blockchain Association as the association that accommodates the use of blockchain in Indonesia. Some of the companies that have joined this association are BLOCKTECH, BlockSphere, Pundi x, Indonesia Blockchain Network, LUNO, INDODAX, BITOCTO, Rekeningku, coinone Indonesia, UPbit, Online Pajak, Tokocrypto, VEXANIUM, GOPAX Indonesia, UDAX, and PLAY GAME. The Indonesian Blockchain Association's vision and mission are to encourage collaboration between the government and businessmen in developing blockchain technology and cryptocurrency in Indonesia.

Some companies have been growing rapidly in the utilization of blockchain in Indonesia, namely Tokoin and HARA Token. Tokoin is a blockchain user that aims to help the MSME bookkeeping and make it easier for banks and non-bank institutions in conducting credit analysis. MSME will send the data of transaction activity through the Tokoin App, then Tokoin will process and validate the data into a valuable asset.
If the transaction data has been entered into the blockchain, then it cannot be changed, that is what makes the data trustable. The transparency in bookkeeping and the constancy of blockchain make it easier for MSME to grab investment since the presented data is trustable [6].

The development of Blockchain in Indonesia attracts the government's interest to use this technology as well. The Chamber of commerce and Indonesian industries have planned to utilize blockchain technology in building the connection of MSME with the logistic service provider and world supply chain. The initial step in the application of blockchain is still on the stage of providing training by creating a platform and application to deliver the learning material [19]. Besides that, Bank Indonesia (BI) is still in the stage of learning blockchain technology to be applied in the payment system in Indonesia. Currently, BI is conducting a study to see the kind of businesses that can use blockchain [14].

OJK allows banks or other financial institutions to utilize blockchain since it can improve the working mechanism of internal banks with a low operational cost which makes it more efficient [5]. Furthermore, the use of blockchain technology in OnlinePajak has been announced in 2018. It is 
expected to support tax transparency and make it easier for the taxpayers to pay. With the implementation of the OnlinePajak blockchain, it will be possible for interested parties to have a record for every transaction of tax payment [13].

Blockchain technology, also known as a global ledger. is very useful for accounting. Sastrowardoyo as the head director of Blockchain Zoo states that the benefit of blockchain for accounting is in terms of time efficiency and data security that allows each party to observe their servers so that there will be no difference in the recording, as well as to avoid data deviation [9]. The payment tool used in blockchain technology is cryptocurrency. According to [12], IFRS and PSAK have not managed the accounting treatment for cryptocurrency. This raises questions of how the accounting records in the blockchain which is also known as a global ledger.

The research of [3] explains that the general ledger available in blockchain removes companies' privacy that might be seen by competitors that are also using this technology. On the other hand, the use of private blockchain can avoid the disclosure of the company's data and make the system to be like a traditional transaction record. Therefore, [3] states that blockchain for accounting is inappropriate. Based on [2], the inappropriateness of accounting in blockchain mentioned by [3] is due to the limited development of blockchain at that time and the fact that their arguments are based on whether blockchain can be used in a double-entry system.

The researcher wants to see the potential of blockchain technology for the accounting field in Indonesia. This research focuses on the Indonesian Blockchain Association as the organization that accommodates the use of Blockchain in Indonesia. This research is also conducted to explore accounting in blockchain according to the current condition of Indonesia.

\section{Blockchain Technology}

Blockchain technology was conceptualized by Satoshi Nakamoto in 2008. [11] research related to how trading through the internet makes the third party or intermediary can be trusted over the transaction between the seller and the buyer. Thus, it can be said that the transaction will be secured as long as there is an intermediary as the guarantor and the transaction will be following the agreement between the seller and the buyer. The intermediary party will ensure that the transaction runs smoothly, the buyer receives the purchased goods, and the seller receives the amount of money based on the agreement that has been done before. However, the cost of the transaction will be increased from how much it should be because there is an additional mediation fee that will be received by the intermediary [11]. [11] expects that the existence of the peer-to-peer-based system will make it easier for buyers and sellers to do transactions with cheaper transaction fees, without the intermediary party as the guarantor, and obviously with more reliability than the guarantee offered by the intermediary.

According to [7], blockchain was implemented in 2009 as a technology that becomes the basis in solving the problem of double-spending for bitcoin. Blockchain is a distributed database that consists of transaction records or digital events that have been executed and shared among the participating parties. Every transaction is verified by the consensus of the majority of participants of the system, which makes it possible to create distributed consensus in the online digital world. Blockchain technology facilitates systems to develop a democratic, open, and scalable digital economy. The characteristics of blockchain technology include excellent features such as smart contracts and smart property [22].

Smart Contract is a part of the blockchain that provides security more than traditional contracts and reduces the transaction cost. The characteristic of a Smart Contract is that the content cannot be manipulated and the implementation cannot be prevented. Smart Contract makes a transparent agreement, conflict-free, and avoids bank intermediary services, lawyers, and notaries in its implementation [15]. Moreover, smart contracts can automate every transaction and quickly create records in blockchain when the required conditions are fulfilled. The rules and the basis of applied accounting records can be arranged in a smart contract so that the recording will be appropriate to what has been expected [4]. According to [18] blockchain is separated into three categories: Blockchain 1.0, 2.0, and 3.0.

- Blockchain 1.0 is a currency. The deployment of cryptocurrency in cash-related applications such as currency transfer, remittance, and digital payment systems.

- Blockchain 2.0 is a contract. The entire list of economy application, market, and financial use blockchain which is wider than simple cash transactions such as stocks, bonds, futures, loans, mortgages, ownership, smart property, and smart contract.

- Blockchain 3.0 is a blockchain application beyond currency, finance, and market in the field of government, health, science, literacy, culture, and arts.

Blockchain technology has emerged as one of several contemporary technologies that have the potential to change business processes significantly, 
particularly the accounting and assurance functions [4]. [1] confirms that even though blockchain attracts a lot of attention from financial institutions, the use case is still in the experimental stage. Blockchain has the potential to change the current accounting form with the existence of smart contracts that can automate the accounting process. According to [1] Blockchain as the source of trust can help the current accounting structure and can gradually integrate with accounting procedures. Starting from securing the integrity of records, audits can track record mistakes easily and automated audits might be realized.

An article from [3] studies the accounting possibilities of blockchain. It is mentioned in their work that accounting in the blockchain is inappropriate due to its lack of credibility. The concept that exists in public or private blockchain cannot remove the inappropriate accounting concept in the blockchain. [3] argues that public blockchain cannot be used by giant companies because they do not want to give their information publicly. Besides that, in a public blockchain, no authority arranges someone to read or verify the records in the blockchain. Meanwhile, the use of private blockchain causes investors or external parties to not be able to directly participate in this network and, consequently, the company's data cannot be published outside the company. Based on [3], the ability to determine ledger entry requires a wide accounting knowledge, which investors do not have. Accountants will be able to know the control needed to prevent profit management, accounting error, and fraud. Therefore, blockchain is not going to remove that need.

In the article written by [4], there are opinions that differ from [3]. According to [4], the accounting profession can gain benefits from blockchain. Blockchain can be utilized to store accounting data safely, and can also share relevant information to all related parties. The use of blockchain technology in a company will produce a new accounting information system that records transaction validation in the ledger. A transaction in the blockchain is not only a monetary exchange between two parties but also the flow of accounting data in a company. This system is believed to produce a real-time report by directly presenting accounting information to related parties such as managers, auditors, creditors, and stakeholders. Smart contracts take an act as automatic control that monitors accounting processes based on the rules that have been established. Blockchain can also use data analysis to find anomalies and other useful information. By using this kind of system, managers, accountants, business partners, and investors can actively collaborate to verify transactions.
Triple-entry accounting was proposed by Gringg in 2005 in [2]. This triple-entry system was proposed to be utilized as an independent and secure paradigm to improve the reliability of a company's financial report. This mechanism needs a reliable independent intermediary to verify every transaction. Blockchain technology has the potential to improve its triple-entry mechanism and reduce the problems of risk manipulation and data deviation. Blockchain plays the role of an intermediary by distributing and automating storage and verification processes while guaranteeing the security that prevents sabotages. This is possible due to the nature of blockchain that keeps the authenticity of the data, which means the data cannot be changed or destroyed. Additionally, smart contracts can activate a quick verification of transaction records by following accounting standards or business rules that have been determined.

According to [4], companies that wish to maintain control over their information by excluding irrelevant parties can do so by using a private blockchain. This system will be more effective and efficient because it needs fewer nodes to confirm the transaction. Blockchain needs verification and therefore, in making verification, it can be done by those who are permitted to do that such as accountants, managers, auditors, and investors. [4] suggests a design of the potential usage of the tripleentry accounting information system by making blockchain an embedded layer in the double-entry system, which in this case is the ERP. Smart contracts will create transaction records that are saved in the blockchain ledger from the transaction records that are recorded in the double-entry system which is the ERP.

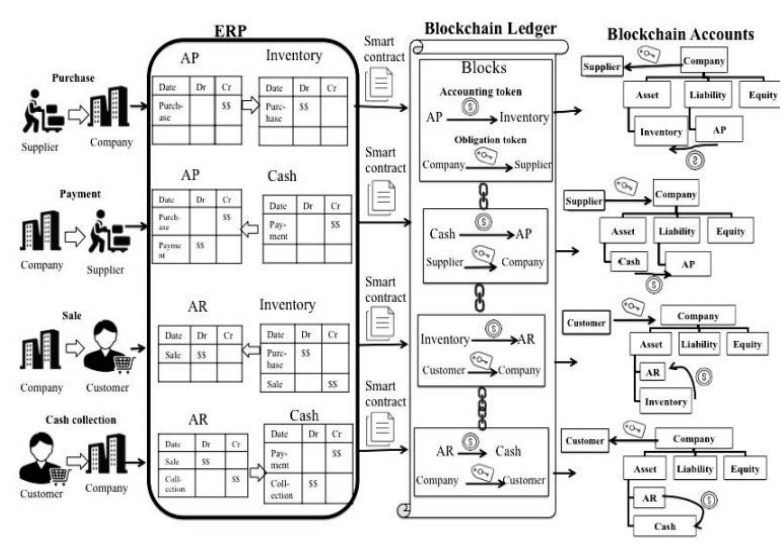

Figure 1. A Triple-Entry Accounting Information System [4]

Moreover, [2] gives an opinion that utilizing blockchain will bring up an accounting method named triple-entry accounting which is more promising than double-entry accounting. This 
research gives an example of a simple transaction between Alice and Bob by using a double-entry system and a triple-entry system. [2] explains that a transaction that uses double-entry tends to cause the risk of error in recording. Thus, it has to be verified by the bank before the transaction is recorded in the internal book. Whenever there are mistakes in checking the records, an auditor needs to check them. The auditor has to check the records from three parties; Alice, Bob, and the bank, which takes a lot of time. Compared to a double-entry, the use of the triple-entry system is effective, transparent, and easier for various parties.

It can be seen from the transaction between Alice and Bob that there will be no mistake because the recording that has been done in the company's internals will be coordinated to the shared ledger: blockchain. Therefore, when the auditor checks the authenticity of a transaction, the auditor only needs to check the records in the blockchain because it depicts the company's internal records. If there are any differences found between the company's records and the blockchain records, the problem of the records will be quickly detected since the records in the blockchain cannot be changed or manipulated.

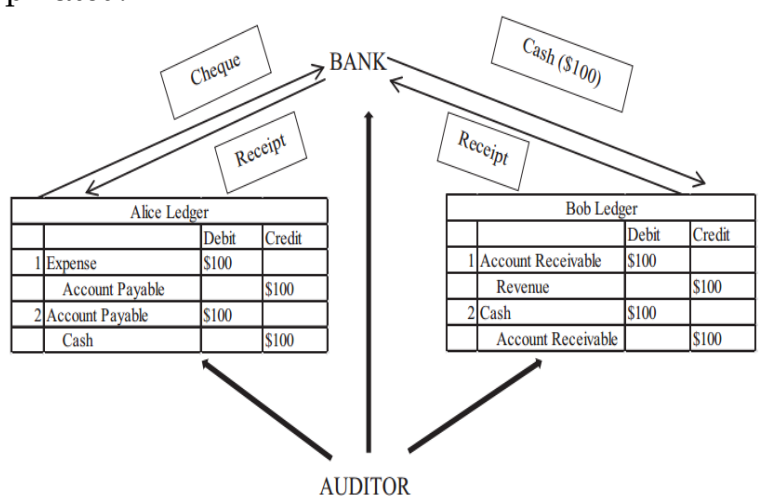

Figure 2. A payment transaction between Alice and Bob in a Double-Entry accounting system [2]

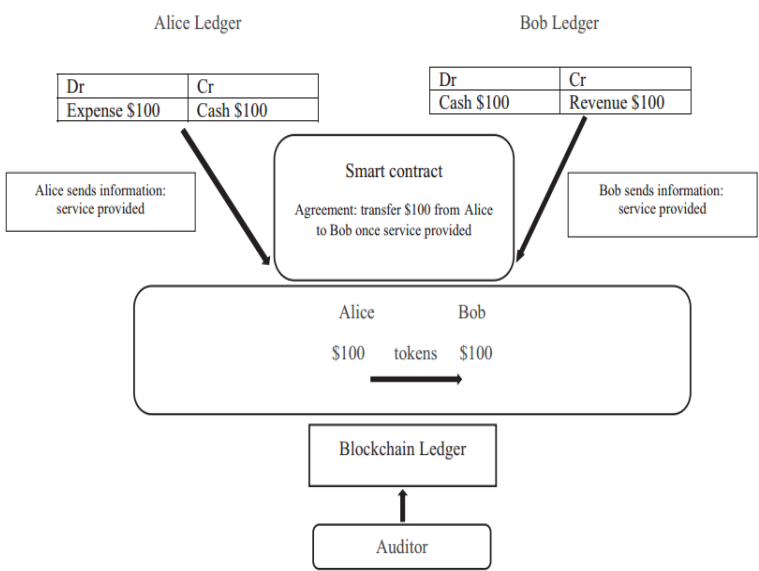

Figure 3. A payment transaction between Alice and Bob in a Triple-Entry accounting system with blockchain [2]
The development of blockchain technology has been explained in the previous three journals which discusses how accounting has been related to this technology. [3] states that accounting in the blockchain is inappropriate. However, [4] argues that the implementation of blockchain will produce a tripleentry accounting system based on the concept created by Gringg which explains that triple-entry accounting will be realized if there is a trustworthy independent party. The framework created by [4], namely the ERP system, will be overlaid by blockchain by using a smart contract as the system that automates the records from ERP to blockchain so that there will be no records difference. Thus, it will be possible for the parties doing the transactions to see and check the authenticity of the transactions.

\section{RESEARCH METHOD}

This study is the initial exploration stage on the 'Exploring Blockchain Potential for the Accounting Field' topic. Since the use of blockchain for accounting is still in the developing stage, this study uses the qualitative approach by emphasizing the case study. The researcher chooses this type of case study due to the purpose of this study, which is to clearly and deeply explore the potential of blockchain for the accounting field. This is in accordance with the perspective declared by [23] which states that a case study is a suitable research for the exploratory strategy. The source of data that is used in this study is primary and secondary data.

This research took place at the Indonesian Blockchain Association. The researcher considered choosing this location because the Indonesian Blockchain Association is an organization that accommodates the use of blockchain in Indonesia. IBA was founded on January 18, 2018, by six local blockchain companies, namely Blocktech Indonesia, Blockchain Zoo, Indodax, Indonesia Blockchain Network, Luno, and Pundi X. Moreover, Indonesian blockchain commits to cooperate with stakeholders including the Ministry of Commerce, Creative Economy Agency, Bank Indonesia, Financial Service Authority (OJK), Report and Analysis Center of Financial Transaction (PPATK), and Indonesian Fintech Association.

This research was conducted through data collection by interviewing informants who were capable of this study. The first informant was the head of the Indonesian Blockchain Association and the second informant was the member and former head of the Indonesian Blockchain Association. The interview was semi-structured which began by introducing the purpose of study and followed by a series of prepared questions. Additionally, the researcher also collected data from Tokoin's white paper as a platform that uses blockchain, to see the utilization of blockchain in Indonesian companies. 
After obtaining the result from the interview with the Indonesian Blockchain Association, each data is transcribed and analyzed according to the context as well as Tokoin's white paper. Furthermore, the researcher combined some previous research to conclude the use of blockchain in the accounting field in Indonesia.

The researcher attaches quotations containing opinions and experiences of the informant related to the blockchain potential in Indonesia. Therefore, quotations are very important for readers to obtain knowledge and concept about the study phenomenon as a form of interpretation [17].

\section{RESULTS AND DISCUSSION}

\section{Accounting side in Blockchain}

[4] explains that accountants can utilize blockchain and smart contracts to store accounting data safely, share relevant information with the interested parties, and improve business data verification. Blockchain can be called an accounting information system, also known as a global ledger. In the interview with Informant 2 as an involved party in blockchain and one of the members of the Indonesian Blockchain Association, she states:

"If we think about it, the point is that the ledger is also accounting. It can be said that blockchain is an accounting system because basically, blockchain is a recording system".

According to Informant 2, there are many functions of blockchain depending on its use. Using blockchain in a data center can remove some items that are needed for complaints. For example, companies that use blockchain no longer need to do auditing. The reason is that the interested parties can trust anything that is recorded in the blockchain and it is more reliable than paper evidence, etc. Before using blockchain, cooperating companies have their accounting system, so if there are any mistakes while recording, it requires reconciliation to find out the correctness of the mistake.

The supply chain, which uses blockchain, can be a top example of this technology's excellence in recording transactions. The use of this technology will eliminate reconciliation between companies in the supply chain and will simplify the task. In the interview, Informant 2 explains:

"Theoretically, if we can use blockchain, the whole supply chain without unifying the system and the accountants, so there is only one accountant... a lot of accountants is also not a matter, but by the blockchain system we can keep the data match. If the data are unexpectedly unmatched, it won't even be accepted".

Based on the interview result from Informant 2 , she exemplifies about supply chain, since the process is sequential, so we can understand the value of using blockchain from an accounting point of view. Every process is carried out, starting from registering goods by farmers to the buyers. The entire journey of the goods will be recorded in the blockchain, so if there is a possibility of a mistake while recording in every division or every company, it can be directly checked in the blockchain without reconciliation. This is possible to do because the records in blockchain are a suite of transactions that are recorded by the system using smart contracts, and when it is already recorded it cannot be changed by anyone.

Informant 2 asserts that every cooperating company has an accountant to record every accounting data. Although, by the existence of blockchain, the whole accountant will be unified into this global ledger system, so the entire accounting data from every company will be trusted.

\section{Blockchain Function for Financial Report}

Informant 2, a member of the Indonesian Blockchain Association explains that blockchain is applicable for financial reports. She explains this in the previous interview with the researcher:

"Is it applicable for a financial report? Yes, it is. However, it is not only blockchain that can be used there. It depends on the level. Basically, blockchain is a recording technology. For example, a financial report. It has its own structure and calculation, then it is recorded by the end. Then, to make a financial report we need to see the business process first, then we need to see the business model, after that we need to see the income and outcome, the historical data, etc. After that, we produce it in the form of a financial report. Then, that financial report must be recorded and saved. In the end, using blockchain is the easiest way. We only need to put it all into the blockchain, then it will be automatically saved".

In the beginning, before the manufacture of financial reports, blockchain can help accountants to ensure that the data which is going to be entered into the financial report is original data and cannot be manipulated by the existence of timestamping when the documents and data transaction and other accounting data entered the blockchain. After the data is entered into the blockchain, the data in the global ledger will be able to be updated if there are any changes found over the accounting process, although the previous data will not be removed or edited. Therefore, every change that occurred will be automatically detected.

Blockchain is also able to help to calculate or compute the record of accounting data in real-time, this can be accomplished by computing nodes which the logic in the smart contract has a calculation. 
Hence, whenever there is a business process such as selling and purchasing or other accounting processes can be automatically recorded based on the logic that has been implanted in the smart contract. However, this does not mean that the entire process was done through blockchain. Blockchain will only assist the process to be recorded in realtime by using smart contracts. The process will still be entered or recorded outside the blockchain by someone to trigger a smart contract over the logic that has been entered. For example, by entering data into the ERP, then the data will be automatically entered into the blockchain.

\section{Transaction Tool}

According to Informant 1, cryptocurrency is a digital currency that is used in blockchain, this raises an opinion that using blockchain means the payment tool must be cryptocurrency. The advantage of blockchain is that it is not limited by cryptocurrency. There are a lot of blockchains that do not even need cryptocurrency such as Hyperledger Fabric.

Indonesia has a regulation that prohibits cryptocurrency as a payment tool. Based on Informant 1 , there are two ways to improve the accounting system based on the blockchain without using cryptocurrency as the payment tool; (1) transaction recording using the token as the representative of Indonesian Rupiah. The token that is used in blockchain as a payment tool to record transactions is not a cryptocurrency but particularly as a representative of physical or financial assets; (2) using blockchain more like a database, this method does not need cryptocurrency or token.

\section{Public and Private Blockchain}

There are two kinds of blockchains, namely private and public. However, the research written by [3] mentions that blockchain is inappropriate for accounting because public blockchain is unable to be used by big companies. After all, they want to prevent their data from being opened publicly. Meanwhile, private blockchain does not publish information outside the company like traditional recordings. Related to this, Informant 2 explains:

"There are a lot of opinions supporting this. Not only non-blockchain people but blockchain people also sometimes support the second opinion which says that private blockchain has no difference from existing databases and ledgers. That could be true in some cases, but can also be false in some cases".

Informant 2 explains that the advantage of blockchain technology cannot be seen by using private blockchain only for one company. The reason is that companies that use private blockchain have entire nodes from blockchain that can control and change the data in it. However, the advantage of private blockchain can be seen if this technology is used by cooperating companies or companies with a lot of divisions and have a very strong autonomy so that each division has its accountant or conglomerate company.

"It doesn't matter if we use private blockchain accounting only for one company. In fact, the value is very, very strong. Can you imagine? Because the point where blockchain has value is when there is something we call a competing interest. There is interest in competing with each other, different interests, though each of the competitors wants to cooperate with each other... They cooperate and also compete about something. That private blockchain will remain valuable if there is a value to use blockchain on a business basis".

According to Informant 1, in Indonesia, it is not appropriate to use a public blockchain because the financial data must be in Indonesia. On the other hand, there are a lot of companies abroad that dare to enter their financial data in a public blockchain, the company only entered the hash and not the data. Hash is a representative of data that is entered into the blockchain. Therefore, when the data changes, the hash is no longer usable.

\section{The Implementation of Blockchain in Tokoin Platform in Indonesia}

Tokoin is a platform that establishes the identity of MSME as a reputation that is acceptable in the business ecosystem. Tokoin creates a better and more modern business ecosystem that offers a valuable partnership to resolve inclusive growth. There are three most trusted solutions offered by Tokoin to help MSME in solving their problem, such as:

1. Building the digital identity of MSME to represent a valid reputation. Business profile, activities, and purchasing behavior is the key for MSME to produce valuable assets in the Tokoin platform. This platform works by collecting data, starting from the KYC process, routine transaction, behavior recording, to credibility making for Tokoin users.

2. Accommodating MSME in utilizing their data to create more funding opportunities. Tokoin provides appropriate technology infrastructure to record and manage transaction data and utilize data by giving value to it.

3. Giving MSME growth opportunities by bringing up business partnerships.

Tokoin's partnership with various institutions allows users to access the necessary services. From 
the user's side, Tokoin will allow users to build their reputation and credibility by tracking user behavior. By then, they can reach any financial institution that aims for business expansion. Meanwhile, financial institutions will gain benefits from an effective consumer acquisition process by replacing the business credit reputation of Tokoin users.

Furthermore, the Tokoin platform has two major characteristics that are explained in the Tokoin whitepaper, such as:

\section{Digital Identity (Business Profile)}

Tokoin uses the digital sector as a facility and privilege to fulfill the MSME necessities over the identity that has reputation and validity. By obtaining the digital business ID, MSME will be able to record and track their business process in the digital ledger and to distribute the credit rating which they built to other partners in the Tokoin ecosystem, all at once. This is a decentralized nature of blockchain technology where there is no central point of authority that records the data. Tokoin aims to create an ecosystem supported by data distribution and simultaneously gives advantages to each participant by implementing blockchain technology in business processes.

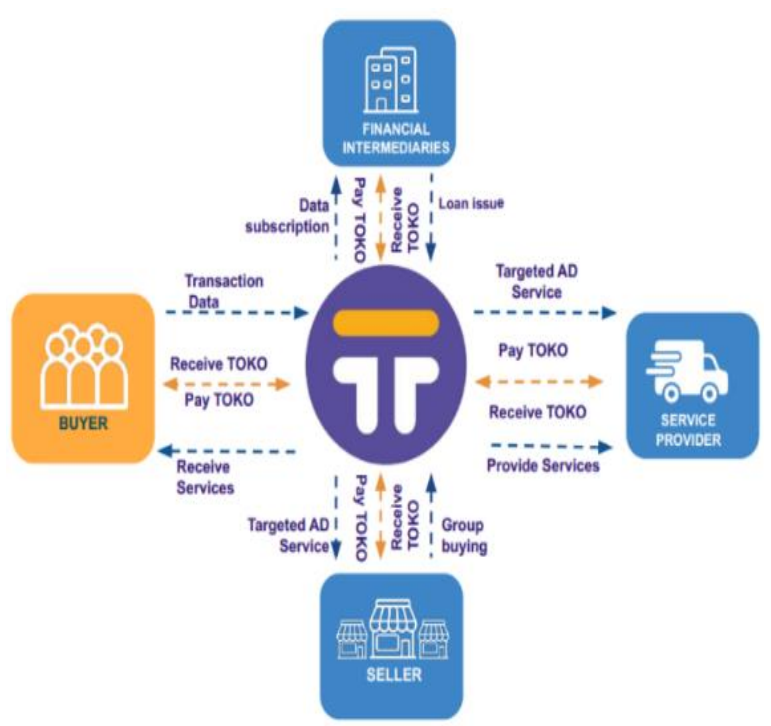

Figure 4. TOKO payment and receipt flow (Tokoin Whitepaper, 2019)

\section{Digital Ledger (Data)}

The entire transaction from the business operation of MSME as Tokoin user will be saved digitally and collectively in a computerized record which is known as a digital ledger. All information starting from KYF to more detailed information such as cash flow, selling, income, and routine business purchasing will be recorded as valuable assets. This asset also will be collected, processed, and given value based on the depth of the information in it. The invested value will be able to become the scoring indicators that build reputation related to the business profile. Data in the digital ledger can be distributed to the Tokoin ecosystem to produce a reciprocal relationship between every participant.

The development of Tokoin is done by creating an ecosystem containing settings arrangements to deliver the experience of distributing values from one participant to others. Each participant has a role to determine that the ecosystem remains beneficial for each invented business. Interaction between user and partner activated by blockchain technology to ensure that each participant has security for every transaction and a more trusted relationship. MSME has a role as data provider and to send data transaction activity through Tokoin App, then Tokoin will process and validate data of valuable assets. After that, the partner can obtain the data by exchanging it with the store token.

\section{Blockchain Impact on Accounting Work in Indonesia}

[4] assumes that accounting professions will benefit from blockchain technology. This technology can be applied to keep accounting data safe and directly share relevant information with interested parties also to improve business data verification. Jobs that are related to accounting will still be needed because the data that will be entered into the blockchain must be processed by someone through other platforms that will be connected to the blockchain. After the data is inputted into other platforms such as the ERP, the data will be automatically recorded into the blockchain according to the computing logic in the smart contract.

According to the explanation of Informant 1, accountants do not have to learn informatics engineering to be able to adapt to blockchain technology, they only need to learn how to operate blockchain. Accountants will still be needed to process information in the blockchain. Although the interested parties understand the concept of blockchain, they do not necessarily have the knowledge related to accounting data analysis. Thus, accountants will remain to do this job.

Accountants do not need to worry about being unemployed due to the implementation of blockchain. Even though this technology has already been implemented, it still needs manpower to operate and accountant skills to analyze the data to produce relevant information for interested parties. 


\section{Blockchain as Accounting Information System}

An accounting information system is a computer-based method to track the accounting and business activity of a company. An accounting information system generally consists of six main components, such as (1) income cycle, which involves the activity of selling products or services and collects payment for the selling; (2) outcome cycle, which involves buy and sell activity and pay for product used by the organization; human resource cycle involves activities related to recruitment and payment of employees; (3) production cycle, includes the activity of changing raw materials and labors into finished good; (4) funding cycle, includes the activity of obtaining funds that needed to run organization, pay for creditors, and distribute profits to the investor. Every transaction of that cycle will be stored in the Accounting Information System database. Outside the data recording of organizational transactions, Accounting Information System fulfills two basic functions: provides useful information to management for decision making and provides proper internal control [21].

Accounting information systems are used as a management tool in gaining information, analyzing, and decision making. The Accounting Information System also has a function as a tool that takes responsibility for the authority delegated by management to subordinate management levels and executor employees. That responsibility will be running well with the help of a system that allows each employee to record and save every event and transaction that occurs systematically, organized, standard, and easy. Therefore, Accounting Information System is a network from the entire procedures, forms, and tools that are used to manage financial data into the form of reports that are used by management to control their business activities and a tool that is used for management decisions making [10].

An accounting Information System is a subsystem of unified business processes that are related to each other. The purposes of the Accounting Information System are: (1) collecting and saving data related to the company's financial activities; (2) processing data into information that is usable for the decision-making process; (3) controlling every aspect of the company [10].

Blockchain is enabled to be a technology for Accounting Information Systems because blockchain can track every form of a company's business activities and transactions in real-time. The existing data in this technology can be relevant and reliable information due to the nature of blockchain technology which is capable of recording and storing data that cannot be changed or manipulated. By using this technology, it will be easier for companies to track and analyze data as a form of decisionmaking in the future.

In Indonesia, blockchain is capable of being used as a database to save transaction documents to improve the authenticity of the data. This is because the data storage process is conducted in real-time by using smart contracts where the entire data can be saved automatically based on the computing logic in the smart contract.

In such a case, using blockchain in the Tokoin platform aims to store the data of MSME activities. Hence, it will be easier for companies or individuals that need information from MSME to identify the activity of MSME in a distributed database, which is the blockchain technology. The displayed data in the blockchain is the company activities that can be analyzed to help in case of decision-making. Therefore, blockchain can be a relevant and reliable accounting information system due to its consistency. Once there are any changes, it will be easy to recognize every change.

According to [20], Accounting Information System is a specific and accessible database by adopting the architecture of multi-tier software. There are three layers in the software of accounting information systems, involving data management level, application level, and presentation level. [20] points out two implications of blockchain-based accounting information systems according to the concept of an accounting information system as a multi-tier database. First, blockchain technology is possible to be implemented at the database engine level where the transaction is arranged, but it seems impossible to replace accounting information systems at the application level. The reason for this is that blockchain is only used as a database that has no relation to the application that changes data into useful accounting information. Therefore, blockchain has been used as a platform to save data before the data is processed into useful information for decision making through the Accounting Information system. The arrangement of financial reports from verified transaction databases and using databases as accounting applications are two different processes.

Second, a blockchain-based Accounting Information System will probably appear in the form of a private blockchain. Accountants will have a nontechnical role in managing the system. There are several advantages from the implementation of private blockchain for accounting information systems in a company, such as the lower risk of accounting management fraud, lower validation cost, and higher compliance with legal requirements of law from main responsibility for accounting information [20]. 


\section{The Concept of Triple-Entry Accounting Blockchain that Applicable in Indonesia}

Mechanism of traditional accounting transaction records based on a double-entry system that is arranged by three parties; payer, payees, and publisher such as made by banks for their customers routinely. Payers send money to payees and publishers (banks) that are responsible to verify and sign the transaction. Following by transferring money, issuing payment receipts for payers and payees to update their bookkeeping. This model gives too much capacity to publishers which can be a strong candidate for internal fraud. To reduce recording mistakes, data manipulation, and the potential of publisher fraud, the accounting tripleentry model guarantees all parties to have similar information, there will be no parties allowed to enter invalid information [16].

The Triple-entry system is proposed to be used as a secure and independent paradigm to improve the reliability of company financial reports. The Triple-entry system requires authorization of transaction process from neutral intermediaries to enable each party to make a transaction record including two parties that are involved in the transaction and intermediaries to produce three entries. This mechanism needs reliable and independent intermediaries in verifying every individual transaction and entries that are saved by intermediaries must be guaranteed from the risk of loss or data changes by hackers or others. Blockchain technology has the potential to become a third party that can record transactions in a triple-entry mechanism [8].

A simple design created by [4] allows recording systems to record transaction information between business parties, also the flow of data within an organization. The recording system will record every transaction which is created in a double-entry system or traditional transaction into a blockchain ledger.

The research of [4] combines blockchain and the ERP system. Blockchain is used as an additional system that overlays the recording in the ERP system, this allows recordings in one company to be integrated into several cooperating companies. Therefore, it will be easier to handle every mistake and transparency in the recording. A regular recording will still be carried out by ERP, then through the smart contract, it will be possible for those recordings to be re-recorded automatically into blockchain by using a token as representative of physical value or financial value that is recorded in ERP.

In their research, [2] and [4] share an example of a blockchain usage concept that generates a different triple-entry accounting. [4] offers their concept to combine blockchain and ERP systems, while [2] offers a concept to use blockchain without combining with any other technologies.

Blockchain is a novelty in Indonesia. Thus, regulation for the implementation is still in the stage of development. According to Informant 1, the type of blockchain that is used in Indonesia is a private blockchain. This enables every company to design its type of blockchain-based on their needs. In Indonesia, the blockchain solution is accompanied by other solutions such as ERP. Therefore, the concept that is used in Indonesia is more likely to be the concept offered by [4]. The condition in Indonesia that does not allow cryptocurrency as a valid payment tool makes every record in blockchain that uses accounting tokens as the representative of physical or financial assets in the ERP recording to the blockchain.

In such a case as Tokoin, blockchain is used as a data recorder where the data of business activities in MSME are constantly being updated into the blockchain, which makes it possible to see the improvement of MSME business activities without any forgery.

It will be easier to analyze the activities and financial data of MSME that will be considered in decision making. Blockchain in Indonesia can be a credible database, concerning the data will be verified by every participating node, Tokoin will have a role to sort the data before the data is entered into the blockchain. Payment in blockchain uses tokens to access data in the Tokoin platform. So, that does not matter even though the regulation in Indonesia rejects cryptocurrency as a payment tool.

\section{CONCLUSION}

Based on this research's result, the researcher concluded that the implementation of blockchain in Indonesia can be applied in two ways. First, transaction recording in blockchain by using a token as an asset representative. Second, the use of blockchain without token or cryptocurrency. The blockchain will be used as a database to store transaction data or any kind of report that is created by using another platform and saved into the blockchain to be checked and given a timestamp by nodes.

Blockchain provides advantages for accounting, particularly for Accounting Information Systems. The recording of transaction data that is previously validated by nodes in the network before the data is dropped into the blockchain is a form of future improvement of the Accounting Information System. Blockchain database facilitates Accounting Information System to browse the relevant data and the data can be used as a reference in organizing 
financial reports. Even though blockchain is a system of data structure that is used in technology and it can automate transaction records by using smart contracts, the accounting job is still needed to analyze and organize financial reports based on the data taken from the blockchain.

The triple-entry accounting concept can be used in Indonesia later by utilizing blockchain as an additional system to record transactions in other platforms such as ERP. The use of blockchain here aims to give a timestamp to every transaction to avoid data manipulation.

\section{Implication}

The result provides several implications. The theoretical implication supports the theory which states that blockchain is an accounting technology that can be applied in Indonesia without having to use cryptocurrency as a tool of payment.

Blockchain can be a database engine for accounting information system applications because an accounting information system is a computer-based method that tracks the accounting and business activity of a company. Blockchain is only used for data security while processing the data into information will still be carried out by the accounting information system. Blockchain cannot automatically process data into information that may be needed in accounting.

The other implication of this study is a practical implication. The triple-entry accounting concept which can be used in Indonesia is a concept that merges blockchain with other applications or platforms such as ERP. This allows the triple-entry accounting model to use tokens as an asset or financial representation in recording the transactions. This uses the private type of blockchain that requires permission to participate in the network. Thus, it will be possible for every company that wants to use this technology to design its blockchain model according to its needs.

The last one is policy implication. Regulations and policies in the case of blockchain use in Indonesia are still under discussion. The result of this study can be used as a reference for new regulations and policies related to the use of blockchain in Indonesia. This study can be an initial basis in releasing regulations concerning the recording and reporting of accounting transactions by using blockchain technology.

\section{REFERENCES}

[1] Andersen, N. (2016). Blockchain Technology A Game-Changer in Accounting?. Deloitte, 1-5. https://www2.deloitte.com/content/dam/Deloit
te/de/Documents/Innovation/Blockchain_A\%2 0game-changer\%20in\%20accounting.pdf

[2] Cai, C. W. (2019). Triple-entry Accounting with Blockchain: How Far Have We Come?. Accounting \& Finance 1-23. doi: 10.1111/acfi.12556.

[3] Coyne, J. G., and McMickle, P.L. (2017). Can Blockchains Serve an Accounting Purpose?. Journal of Emerging Technologies in Accounting 14(2):101-11. doi: 10.2308/jeta-51910.

[4] Dai, J., and Vasarhelyi, M. A. (2017). Toward Blockchain-Based Accounting and Assurance. Journal of Information Systems, 31(3):5-21. doi: 10.2308/isys-51804.

[5] Franedya, R. (2018). OJK: Teknologi Blockchain Penting Untuk Ekonomi Digital. Retrieved November 8, 2019. https://www.cnbcindonesia.com/tech/20180715152756-37-23615/ ojk-teknologi-blockchain-penting-untuk-ekonomi-digital.

[6] Gamar, R. (2019). Lewat Tokoin, UMKM Bisa Mengembangkan Usaha Berbasis Teknologi Digital. Retrieved November 8, 2019 https://regional.kompas.com/read/2019/03/05/ 11532301/lewat-Tokoin-umkm-\%09bisamengembangkan-usaha-berbasis-teknologidigital.

[7] George, R. P., Peterson, B. L., Yaros, O., Beam, D. L., Dibbell, J. M., \& Moore, R. C. (2019). Blockchain for business. Journal of Investment Compliance, 20(1), 17-21. https://doi.org/10. 1108/joic-01-2019-0001

[8] Ibañez, J. I., Bayer, C. N., Tasca, P., \& Xu, J. (2020). REA, triple-entry accounting and blockchain: Converging paths to shared ledger systems. ArXiv, 1-56. https://doi.org/10.2139/ ssrn.3602207

[9] Indopos.co.id. (2018). Teknologi Blockchain Berikan Banyak Manfaat untuk Sektor Akuntansi. Retrieved November 8, 2019. https://indopos.co.id/read/2018/05/05/136991/teknologiblockchain-berikan-banyak-manfaat-untuksektor-akuntansi/

[10] Marina, A., Wahjono, S. I., Syaban, M., \& Suarni, A. (2017). Sistem informasi akuntansi: Teori dan Partikal. Surabya: UMSurabaya Publishing.

[11] Nakamoto, S. (2008). Bitcoin: A Peer-to-Peer Electronic Cash System | Satoshi Nakamoto Institute. In 2008-10-31.

[12] Nuraliati, A., \& Azwari, P. C. (2019). Akuntansi Untuk Cryptocurrency. I-Finance: $A$ Research Journal on Islamic Finance, 4(2), 131-142. https://doi.org/10.19109/ifinance.v4i2.2885

[13] Onlinepajak. (2018). Blockchain dan Pemanfaatannya di Indonesia. Retrieved November 8, 2019. https://www.online-pajak.com/blockchain. 
[14] Rossiana, G. (2018). BI Pelajari Blockchain untuk Sistem Pembayaran Indonesia. Retrieved November 8, 2019. https://www.cnbcindonesia.com/tech/20180410135854-37-10389/bipelajari-blockchain-untuk-sistem-pembayaran-indonesia

[15] Sadiku, M. N. O., Eze, K. G., \& Musa, S. M. (2018). Smart Contracts : A Primer. Journal of Scientific and Engineering Research, 5(5), 538541. https://www.researchgate.net/publication/ 326752872_Smart_Contracts_A_Primer

[16] Simoyama, F. D. O., Grigg, I., Bueno, R. L. P., and Oliveira, L. C. D. (2017.) Triple Entry Ledgers with Blockchain for Auditing. International Journal of Auditing Technology, 3(3):163. doi: 10.1504/ijaudit.2017.10007789.

[17] Suryani, A. W., and Helianti, U., (2020.) Rigour in Qualitative Studies: Are We on Track?, Jurnal Akuntansi Dan Keuangan, 22(2):4758.
[18] Swan, M. (2015). Blockchain for a New Economy. Sebastopol: O'Reilly Media. https://epdf. pub/download/blockchain-blueprint-for-a-neweconomy.html

[19] Syarizka, D. (2019). Apa Manfaat Blockchain bagi UMKM?. Retrieved November 8, 2019. https://teknologi.bisnis.com/read/20190730/84/ 1130223/apa-manfaat-blockchain-bagi-umkm

[20] Tan, B. S., \& Low, K. Y. (2019). Blockchain as the Database Engine in the Accounting System. Australian Accounting Review, 29(2), 312-318. https://doi.org/10.1111/auar.12278

[21] Trigo, A., Belfo, F., \& Estébanez, R. P. (2016). Accounting Information Systems: Evolving towards a Business Process Oriented Accounting. Procedia Computer Science, 100, 987-994.

[22] Wang, H., Chen, K., \& Xu, D. (2016). A maturity model for blockchain adoption. Financial Innovation, 2(1), 12.

[23] Yin, R. K. (2018). Studi Kasus: Desain dan Metode. Depok: Rajawali Pers. Metode. Depok: Rajawali Pers. 